
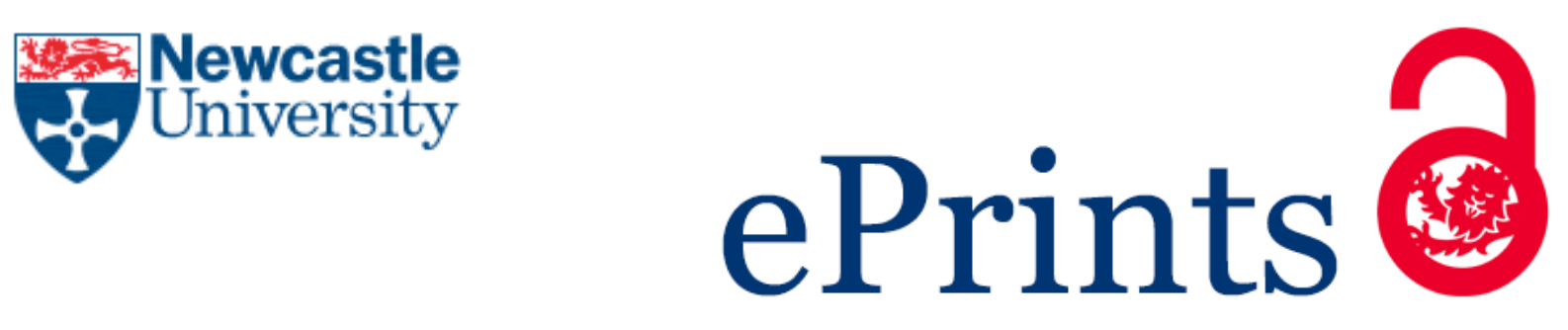

Hansen CK, Christensen A, Rodgers H, Havsteen I, Kruuse C, Nybing J, Kaasbol M-A, Christensen $\mathbf{H}$.

CT and MRI-based door-needle-times for acute stroke patients a quasirandomized clinical trial.

Clinical Neurology and Neurosurgery 2017, 159, 42-49.

\title{
Copyright:
}

(C) 2017. This manuscript version is made available under the CC-BY-NC-ND 4.0 license

DOI link to article:

https://doi.org/10.1016/i.clineuro.2017.05.011

Date deposited:

$31 / 08 / 2017$

Embargo release date:

10 May 2018

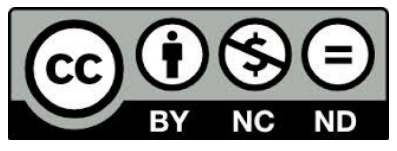

This work is licensed under a

Creative Commons Attribution-NonCommercial-NoDerivatives 4.0 International licence 


\title{
CT and MRI-based Door-Needle-Times for acute stroke patients
}

\section{A quasi-randomized clinical trial}

\author{
Christine Krarup Hansen ${ }^{1}$, Anders Christensen ${ }^{2}$, Helen Rodgers ${ }^{3}$, Inger Havsteen ${ }^{2}$, \\ Christina Kruuse ${ }^{4}$, Janus Nybing ${ }^{2}$, Mari-Anne Kaasb $\left.\varnothing\right|^{2}$, Hanne Christensen ${ }^{1}$. \\ ${ }^{1}$ Department of Neurology, Bispebjerg Frederiksberg Hospital, University of Copenhagen, Denmark \\ ${ }^{2}$ Department of Radiology, Bispebjerg Frederiksberg Hospital, University of Copenhagen, Denmark \\ ${ }^{3}$ Stroke Research Group, Institute of Neuroscience, Newcastle University, Newcastle, United \\ Kingdom \\ ${ }^{4}$ Department of Neurology, Neurovascular Research Unit, Herlev Gentofte Hospital, University of \\ Copenhagen, Denmark
}

\section{Abstract:}

\section{Objectives:}

Door-Needle-times (DNT) of 20 minutes are feasible when Computer Tomography (CT) is used for first-line brain-imaging to assess stroke-patients' eligibility for intravenous-tissue-PlasminogenActivator (iv-tPA), but the more time-consuming Magnetic Resonance Imaging (MRI)-basedevaluation is superior in detecting acute ischaemia.

The aim of this study was to compare DNT for CT versus MRI-based acute stroke-evaluation.

\section{Patients and Methods:}

Consecutive acute stroke-patients admitted to an acute stroke-unit were quasi-randomized to CT or MRI-based assessment and treated with iv-tPA, if eligible.

Door-Decision-Time and DNT for CT versus MRI-examined patients were compared and predictors of treatment-delay identified.

The effect of using MRI as the primary imaging-strategy upon the modified-Rankin-Scale (mRS) at three months was assessed using the validated electronic COMPASS-tool.

\section{Results:}

Four-hundred-forty-four patients were included. Median DNT in CT-allocated patients (22 (IQR 16) min) was significantly shorter than in MRI-allocated patients (30 (IQR 14) min), p=0.005.

The COMPASS-tool predicted that chance of independent living $(\mathrm{mRS}<3)$ at 3 months decreased with $1 \%$ in $16.9 \%$ of iv-tPA-treated MRI-examined patients due to the median treatment-delay of 8 minutes. In MRI-allocated patients; MRI were not feasible in $23.7 \%$ due to contraindications, in 
$16.1 \%$ due to clinical conditions and in $6.8 \%$ due to organizational issues. $16.8 \%$ of CT-allocated patients (pregnant/ $<30$ years) received MRI to avoid X-ray irradiation or due to doubtful clinical presentation of stroke requiring MRI confirmation prior to receiving tPA.

\section{Conclusions:}

CT-based acute stroke evaluation is significantly shorter more feasible than MRI-based evaluation and potentially translates into time-related superior long-term outcome. However, the clinical impact is not detectable.

\section{Introduction:}

The ideal primary radiological image-modality used for evaluation of patients with symptoms of acute stroke prior to administration of intravenous-tissue-Plasminogen-Activator (iv-tPA) must be: Of diagnostic quality, short duration to diminish treatment-delay, feasible in the majority of patients and suitable for examination of restless, claustrophobic or critically ill patients. The ability to safely exclude intracerebral hemorrhage and stroke-mimicking pathologies contraindicating ivtPA is further imperative. Demonstration of early signs of ischemia is not an indispensable requirement but is helpful in patients with atypical clinical presentations.

The pros and cons of Computer-Tomography (CT) versus Magnetic-Resonance-Imaging (MRI) to evaluate patients with symptoms of acute stroke prior to intravenous-tissue-PlasminogenActivator (iv-tPA) treatment have been widely debated. CT-based Door-to-Needle-Times (DNT) of 20 minutes have been proven feasible (1) motivated by time-dependent efficacy of iv-tPA, but the more time-consuming MRI-based evaluation may provide additional information about hyperacute cerebral ischemia (2) and iv-tPA-contraindicating stroke-mimicking pathology.

To answer the question if $\mathrm{CT}$ or MRI is the optimal imaging-strategy in the evaluation of patients with symptoms of acute stroke, a single-center quasi-randomized clinical-trial was conducted to compare several aspects of CT and MRI-based acute stroke-evaluation prior to administration of iv-tPA.

The aim of this preplanned sub-study was to compare DNT and perform a simulated prediction of the difference in long-term outcome between $\mathrm{CT}$ and MRI-examined patients.

\section{Patients and Methods:}

This quasi-randomized clinical-trial included all consecutive patients ( $>17$ years of age) admitted with symptoms of acute stroke within 4.5 hours from symptom-onset to a single hyper-acute stroke-unit, on even weekdays from 8a.m. to 3p.m., from December 2013 to November 2015. All patients from the Region of Copenhagen (1.7 million) are referred directly to our institution on even dates and to another University-hospital on uneven dates. 
In summary, all patients were by the emergency-service directly brought to a dedicated strokeroom within the Department of Radiology and were then evaluated according to a fast-track setup. The patients were met by a pre-notified stroke-team; comprising a neurologist, a stroke-nurse, a neuro-radiologist, two radiographers and an orderly. The team members worked simultaneously, each with well-defined allocated tasks.

The neurologist was a senior-stroke-neurological-consultant ( $n=6$, seeing $74.5 \%$ of the patients), a certified neurologist ( $n=4$, seeing $12.8 \%$ of the patients) or a neurological-resident in the final six month of training prior to full neurological certification under telephone-supervision of a seniorstroke-neurological-consultant ( $n=14$, seeing $12.6 \%$ of the patients).

If eligible, patients were treated with iv-tPA and if appropriate with endovascular therapy after the allocated imaging had been performed.

\section{Randomization and imaging:}

All patients were quasi-randomized to receive $\mathrm{CT}$ or MRI according to an equal number of predefined CT and MRI-days that were stated in calendar posted in the Department of Radiology well in advance.

In a quasi-randomized trial, patients are systematically allocated according to a predefined system (such as alternation, date of birth, case record number or as in our case according to admission date).

All patients were systematically assessed according to a Standard-Operational-Plan (SOP) for undertaking CT and MR imaging. The SOP was strictly followed in accordance with allocation but allowed for predefined cross-over between the $\mathrm{CT}$ and MRI in case of contraindications or vital medical needs for MR or CT such as: suspicion of intracerebral malignancy; MRI incompatible implants; lack of reliable information about MRI contraindications; too large body size; severe illness or restlessness that MRI was not safe; pregnant; less than 30 years of age. MRI-safety was adhered to according to International Guidelines.

On CT-days, a non-contrast-CT of cerebrum (scan-time 17.3 seconds) was conducted followed by a CT-angiography (scan-time 31.6 seconds) if no contraindications, preferably after administration of the iv-tPA-bolus.

On MRI-days, patients had DWI, Flair and Gradient sequences (scan-time 6.4 minutes) followed by a Time of Flight-(TOF)-angiography (scan-time 7.0 minutes), preferably after administration of the iv-tPA-bolus.

If the iv-tPA was administered before the angiography, the angiography was conducted immediately after administration of the tPA-bolus and thus no later than two minutes after the initiation of the tPA-therapy. The patient remained on the scanner bed throughout image conduction and administration of the tPA. 
The neuro-radiologist planned the image-conduction in collaboration with the CT and MRItechnicians when pre-notified of an incoming patient. No patients were allowed to wait for more than 10 minutes for the allocated imaging to be performed; if the radiological staff foresaw that the allocated image-modality would not be available in time, a cross-over was arranged to avoid treatment-delays in accordance with the SOP.

The imaging was assessed by a neuro-radiologist who read the imaging directly in the controlroom before passing on the conclusion to the stroke-physician.

On MRI-days three 20 minutes time-slots were reserved for the trial; when acute MRI-allocated stroke-patients arrived, the MRI-technicians were as a consequence able to catch-up on the preplanned MRI-examinations and thus fully exploit the MRI-capacity.

\section{Sample size:}

As no preceding equivalent trials have been conducted, sample-size was estimated based on an anticipated difference in DNT of MRI and CT-based assessment. With a least clinically relevant difference of 10 minutes, SD at 20 minutes, $\alpha$-two-tailed at 0.05 and $\beta$ at $90 \%$, the total number of participants was estimated at 172 patients. The sample-size was extended in order to allow for secondary outcomes not reported in this sub-study.

\section{MRI-safety:}

On MRI-days, MRI-safety-procedures were strictly adhered to. To reduce the time taken to complete the safety-procedures an MRI-radiographer was present when the neurologist completed the MRI-safety-checklist rather than duplicating the procedure in the MRI-suite.

Outside the MRI-room, a short time-out was imposed to ensure that the MRI-safety-checklist had been reviewed and loose metal-objects removed from both patient and staff-members entering the MRI-room.

A pilot-period of two weeks preceded the trial to ensure high efficiency and staff-awareness in regard to the new time-saving MRI-safety-routines.

\section{Time-registration:}

To ensure a consistent time-registration, intervals from admission to treatment-decision (DoorDecision-Time (DDT)) and to administration of the iv-tPA-bolus (DNT) were recorded systematically.

Symptom-onset was defined as witnessed stroke-symptom-onset or when the patient was last seen well. Admission was defined as when the patient entered the dedicated stroke-room at 
which point the stroke-nurse finalized the electronic patient-registration. Time from arrival of the ambulance to the patient entered the stroke-room was less than one minute.

The time of the treatment-decision was defined as when the stroke-physician decided to prescribe or refrain from prescribing iv-tPA-treatment.

Time of iv-tPA-administration is a mandatory part of the stroke-patient-file from which the time of iv-tPA-administration was later extracted.

The number of patients evaluated during a shift (by the same stroke-physician) and 20-minute time-intervals between arrivals of patients were calculated.

\section{Outcomes:}

National Institute of Health Stroke Scale (NIHSS) and pre-onset modified Rankin Scale (pre-mRS) were on admission established by the stroke-physician.

As part of the institutional follow-up, the iv-tPA-treated patients were by telephone contacted by an outpatient-nurse who recorded the mRS at three months.

The COMPuterised decision Aid for Stroke thrombolysiS (COMPASS)-app $(3,4)$ is validated for prediction of the risk of iv-tPA-induced Symptomatic-Intracerebral-Hemorrhage (SICH) according to the SITS-MOST-definition, mortality, independent living $(\mathrm{mRS}<3$ ) and dependent living ( $\mathrm{mRS} 3$ 5) at three months after iv-tPA treatment. The app gives the risk (in percent) of each of the four outcomes based on entering of the patient's individual risk profile; age, gender, diabetes, previous stroke, presence of recent infarct on $\mathrm{CT}$ or MRI, daily use of aspirin/clopidogrel, time from onset to iv-tPA-treatment (ONT), glucose-concentration, systolic blood-pressure and NIHSS.

We used the COMPASS-app to predict the four outcome-measures for each individual iv-tPAtreated MRI-allocated patient in different two scenarios; 1 , the actual scenario where the patient is admitted on an MRI-day (imitating admission to a primary MRI-based stroke center) 2, a theoretic scenario where the patient instead is admitted on a CT-day (imitating admission to a primarily CT-based stroke center). The two predictions were based on entering of the true individual ONT and the true ONT subtracted the median difference in ONT between MRI and CTallocated patients respectively (the treatment-delay caused by MRI compared to CT-based assessment). All other predictors remained fixed. The four outcomes where thus predicted twice for each patient; an individual prediction illustrating admission on an MRI versus a CT-day respectively. The predicted four paired outcomes were compared for each iv-tPA-treated MRIallocated patient.

\section{Statistical analysis:}

Continuous data were compared with students-t-test and non-parametric continuous data with Mann-Whitney-U-test. Categorical data were compared with Chi-square-tests.

Two random-effects-models allowing for the cluster-effect of the stroke-physicians each seeing more than one patient were constructed to identify predictors of DDT and DNT, the latter only for iv-tPA-treated patients. The following variables were tested as predictors of DDT and DNT in both 
models; age, gender, conducted image-modality, crossover from allocated scan, NIHSS, strokephysician-seniority, time to arrival of the next patient (20-minute intervals) and the numbers of patients evaluated during the shift by the same stroke-physician. Discharge-diagnosis (ischemic stroke, Intracerebral Hemorrhage, TIA or stroke-mimicking-diagnosis), pre-onset mRS, and if thrombolysis was prescribed were furthermore added to the model testing predictors of DDT. DDT and DNT were log-transformed to comply with test-assumptions. The presented estimates, Standard-Errors and 95\% Confidence-Intervals ( $\mathrm{Cl})$ (table 7+8) were back-transformed.

To check for a learning-effect on DNT, DNT were tested with simple linear-regression as function of the consecutive patient-IDs to assess for systematic changes in DNT as consequence of gained experience among the stroke-team-members and institutional use of hyper-acute MRI.

$\mathrm{mRS}$ at three months for CT versus MRI-allocated iv-PA-treated patients were compared with ANCOVA adjusted for the pre-onset mRS.

Due to cases of cross-over between image-modalities, data are presented according to allocation (intention-to-treat) as well as according to the image-modality performed (per-protocol).

Statistical analyses were conducted using SAS-Enterprise (Version 7.11, Cary, NC, USA) and IBM SPSS-Statistics (Version 20.0, IBM Corp, Armonk, NY, USA).

The trail was approved by the Copenhagen-Regional-Ethics-Committee (H-4-2013-118) and the Danish Data-Protection-Agency (2007-58-0015) and registered at ClinicalTrials.gov (NCT02780843).

\section{Results:}

Four-hundred-forty-four consecutive patients presenting with symptoms of acute stroke within 4.5 hours from symptoms-onset were included into this study (fig 1). Two-hundred-twenty-five patients were quasi-randomized for CT and 219 for MRI.

Due to contraindications or when it was not possible to be sure about MRI-contraindications, cross-overs to CT-assessment were done in 52 (23.7\%) MRI-allocated patients (table 1). In addition there was cross over for 40 (16.1\%) MRI-allocated patients due to clinical conditions which required a CT-assessment and further 15 (6.8\%) patients due to organizational issues. Twenty-two (9.8\%) out of $225 \mathrm{CT}$-allocated patients received a MRI head scan: to avoid X-ray irradiation in a pregnant patient; 5 patients were $<30$ years; and further 16 patients had a doubtful clinical presentation of stroke which required MRI confirmation prior to receiving tPA.

Baseline-characteristics according to allocation are presented in table 2 and according to actual image-modality conducted in table $3+4$.

Of the total number of patients presenting with symptoms of acute stroke, 140 (29.7\%) were treated with iv-tPA of which 8 (5.7\%) were later discharged with a stroke-mimic diagnosis. 


\section{Duration of CT and MRI-based evaluation:}

For iv-tPA-treated patients, the median DNT for CT-allocated patients was eight minutes shorter than for MRI-allocated patients $(p=0.004)$ (table 5$)$. For patients with ischemic stroke, both CTbased DDT and DNT were significantly shorter; both according to allocation $(p<0.005)$ and according to actual image-modality performed $(p<0.002)$ (table $6+7)$.

For patients with discharge-diagnosis of ICH, TIA or stroke-mimics, DDT was not significantly different for CT-based and MRI-based evaluation (table 5-7).

The time from admission to image-initiation (Door-Scan-Time (DST)) was significantly shorter on CT-days for both Ischemic stroke and TIA-patients, both according to allocation and imaging conducted without cross-overs (table $5+6$ ).

No systematic time-dependent change in DNT were observed during the trial-period for CT ( $p=0.277)$ nor MRI $(p=0.777)$-based assessment.

\section{Predictors of DDT and DNT:}

Only MRI-allocation predicted DDT (table 8) and DNT (table 9) when allowed for the cluster-effect of the stroke-physicians and adjustment for; age, gender, stroke-severity, cross-over, strokephysician-seniority, the business of the shift and for DDT in addition for pre-onset-mRS, dischargediagnosis and additional image-sequences added to the SOP.

Compared to MRI-allocated patients, the multilevel-models predicted a $24.0 \%$ shorter DDT $(p=0.0001)$ and a $27 \%$ shorter DNT $(p=0.008)$ for CT-allocated patients, table $8+9$.

\section{Modified Rankin Scale at three month for iv-tPA-treated patients:}

Pre-mRS did not differ for CT (median 1.0 IQR 3.0) versus MRI-allocated (median 0.0 IQR 2.0) ivtPA-treated patients ( $p=0.096)$.

When adjusted for pre-mRS, mRS at three month did not differ between CT ( $n=72$, median 2.0 IQR 2.0) and MRI ( $n=60$, median 1.0 IQR 4.0) allocated iv-tPA-treated patients, $p=0.275$.

\section{Predicted long-term outcome for MRI-examined patients due to treatment-delay:}

When the paired predicted four outcomes were compared for each patient, only the chance of independent living differed between the two scenarios: Admission of a CT versus and MRI-day. The COMPASS-tool did not for any of the iv-tPA-treated MRI-allocated patients predict a change in the risk of $\mathrm{SICH}$ or death within three months as a consequence of the median 8 minutes longer MRI-allocated assessment.

For elven (16.9\%) of the 65 iv-tPA-treated MRI-allocated patients the predicted chance of independent living $(\mathrm{mRS}<3)$ at 3 months increased with $1 \%$ when the patient's individual prediction were repeated with an 8 minutes shorter ONT; equaling the patients' true individual 
ONT subtracted the 8 minutes difference between the median DNT for CT and MRI-allocated patients (table 5). The difference in predicted chance of independent living if admitted on a CT versus an MRI-day did not exceed one percent for any of the 65 iv-tPA-treated MRI-allocated patients.

\section{Discussion:}

DNT were 8 minutes shorter for CT-allocated patients compared to MRI-allocated patients; a timedifference that by simulated prediction decreased the chance of independent living at 3 months with $1 \%$ in $16.9 \%$ of the MRI-allocated iv-tPA-treated patients.

MRI was not feasible in $23.7 \%$ of the MRI-allocated patients due to MRI-contra-indications and in additional $14.2 \%$ due to clinically conditions not compatible with safely conduction of MRI of diagnostic quality. In $9.8 \%$ of the CT-allocated patients MRI was conducted to avoid X-ray irradiation in pregnant or young patients or to establish the correct diagnosis prior to potential ivtPA administration.

So far no previous randomized trial has compared DNT for CT versus MRI-allocated strokepatients. This quasi-randomized trial comparing CT versus MRI as first-line of brain-imaging in acute stroke patients was conducted in a stroke-unit conducting approximately 300 iv-tPAtreatments each year. The iv-tPA-function is based on a well-organized set-up with guidelines for both evaluation and acute stroke-treatment.

The study shows that MRI is a potential option in the acute stroke-setting - though significantly slower and less often feasible than CT. The study does not allow for assessment of the potential additional and clinically useful image-information gained when patients have MRI.

The quasi-randomization allocated the patients into two well-balanced groups though males were more prevalent in the MRI-allocated group.

The per-protocol-groups differed in both numbers and baseline-characteristics due to diverse clinical presentations, inherent MRI-contraindications and in some cases need of additional imaging.

We wished to compare the use of $C T$ and $M R I$ in a clinical setting with patients reflecting patients with symptoms of acute stroke being brought to an acute stroke-unit for iv-tPA-assessment. Consequently no inclusion and exclusion-criteria were applied apart from a lower age limit and ivtPA-treatment-initiation within 4.5 hours from onset. Consequently the cohort includes patients with discharge-diagnosis of stroke, TIA as well as stroke-mimicking conditions.

We did not observe a change in DNT for either CT or MRI-allocated patients throughout the trialperiod, indicating that a potential gained accumulative experience of the stroke-team did not influence the effectiveness of the patient-assessment. 
Our MRI-protocol to rule out ICH prior to iv-tPA takes a total of 6.4 minutes compared to 17.3 seconds for the non-contrast CT head. Shorter MRI-based protocols have been introduced (5) and could if used potentially have reduced the 8-minutes time-difference between CT and MRI-based evaluation. As previously reported (6), the interpretation of MRI-sequences can be initiated while the MRI is still underway contrary to how the CT-head must be completed before the imageinterpretation can be begun; consequently at least part of the treatment-delay caused by the longer MRI-protocol is reduced.

Further MRI-safety is imperative and prolongs DNT in ways not inflicting CT-based evaluation; no time is devoted on ruling out MRI-contraindications or physical agitation affecting the diagnostic image-quality is less pronounced. Even instructions and positioning of the patient in the MRIscanner are usually more time-consuming compared to CT.

In Helsinki (1), patients were transferred directly from the ambulance-stretcher to the CT-bed which is not feasible in a MRI-based acute setting as contraindications needs to be ruled out before the patient enters the MRI-room. To unify and thus be able to compare the CT and MRIbased setup, all patients were received in the dedicated stroke-room on CT as well as MRI-days.

Due to a limited number of patients, we were not allowed to test further predictors of DDT and DNT in our random-effect-models.

We did not identify seniority of the stroke-physician as well as the work-intensity during the shift as predictors of DDT or DNT.

As previously reported, nor gender or age of the patient $(7,8)$ or stroke-severity on admission $(7)$ predicted DNT.

As no patients were missed and DDT and DNT were registered for all patients, patient-bias does not influence the DNT-related results but for a total of 8 iv-tPA-treated patients it was not possible to obtain the three-month-follow-up mRS by telephone.

Neither allocation-concealment nor blinding of patients and stroke-team-members were possible due to the clinical quasi-randomized setup and the nature of the CT and MRI-equipment.

The allocation demonstrates a scenario of a hospital being either CT or MRI-based with MRIcontraindications and clinical indications enforcing cross-overs from the primary chosen imagemodality. Deviations from the allocated imaging, on both CT and MRI-days potentially prolong DNT, though cross-overs were not identified as predictors of DDT or DNT in our random-effectmodel.

Hundred-seven (48.9\%) of the MRI-allocated patients and 22 (9.7\%) of the CT-allocated patients had a cross-over to the non-allocated image-modality. Detection of a pacemaker, ferromagnetic implants or a body size too large to fit in the MRI-scanner are objective exclusion criteria, whereas 
assessment of critically ill patients' suitability for MRI is based on empirical experience and a situational evaluation of the individual patient. Unlike previous studies (17, 20, (9), we did not use immobilization of the patients' heads or upper extremities or medical sedation to increase the number of MRI eligible patients otherwise too agitated for MRI of diagnostic quality. Nor did we use MRI-compatible monitoring of vital values or excluded patients with substantial functional deficits to increase the frequency of MRI-eligible patients $(17,20)$. Previous studies on selected acute stroke patients have reported MRI-contraindications in $3.1-12.4 \%$ of the examined patients $(15,17-19)$. Singer et al (10) further excluded acute stroke patients with reduced pre stroke functional status ( $m R S>1$ ) who are more likely to have comorbidities resulting contraindications to MRI. Consequently our population included a higher number of patients with MRIcontraindications (23.7\%) compared to the previous reported studies.

This single-center trial includes patients with mixed socioeconomic-status being admitted to an acute stroke-unit in a public Danish hospital; no private hospitals accept acute stroke-patients. We believe that our results generalizes what needs to be done in the acute setting; the patienthistory and blood-samples should be obtained, the physical examination performed and imaging conducted and interpreted to rule out ICH prior to iv-tPA-administration (1). The trial was conducted on weekdays during daytime and does thus not generalize to off-hours and weekends.

Though the COMPASS-simulation-tool predicted that chance of independent living at 3 months decreased with $1 \%$ in $16.9 \%$ of the iv-tPA-treated MRI-allocated patients due to the median treatment-delay of 8 minutes compared to CT-allocated patients, it is important to stress that the inferior outcome in MRI-examined patients is based on predictions and not true established longterm outcomes. Further did the mRS at three months indeed not differ between our iv-tPAtreated $\mathrm{CT}$ versus MRI-allocated patients. The comparison was though based on a limited number of CT versus MRI-allocated patients and is likely not sufficiently powered. Long-term outcome has further previously been reported to be influenced by various patient-dependent factors (11-17). It is likely that a trial with a greater number of patients would be able to detect a difference in outcome between $\mathrm{CT}$ and $\mathrm{MRI}$-allocated patients.

To justify a potential time-related reduction in long-term outcome MRI must contribute with a higher diagnostic quality; in terms of a higher level of treatment-certainty or better still a lower frequency of iv-tPA-induced complications due to a more qualified selection of iv-tPA-candidates. As a large number of the patients were not able to have an acute MRI, use of MRI as first-line of brain-imaging is not uncomplicated. It is essential to have access to acute CT in case of patients with contraindications or patients unfit for MRI. Finally if MRI-based, one must consider the potentially treatment-delay in patients in need of CT instead of MRI. 
Collaborating previous studies $(1,18)$, we had a low frequencies of iv-tPA treated patients with stroke-mimicking discharge-diagnosis in both the $\mathrm{CT}$ and the MRI-allocated groups; proving that fast and efficient assessment is attainable without compromising a high number of non-eligible patients.

\section{Conclusion:}

CT-based evaluation is significantly faster and more feasible than MRI-based assessment. In simulated prediction, the MRI-induced treatment-delay of 8 minutes potentially translates into a $1 \%$ decreased chance of independent living ( $m R S<3$ ) at 3 months in $16.9 \%$ of the iv-tPA-treated $\mathrm{MRI}$-allocated patients - though not supported by the clinically reported $\mathrm{mRS}$ at three months.

\section{Conflicting interests:}

The Authors declare that there is no conflict of interest

\section{Acknowledgment:}

We are very grateful for the dedicated participation and support from all members of the stroketeam at Bispebjerg-Frederiksberg-University-Hospital.

\section{Funding:}

The trial was fully funded by the Danish Tryg Foundation.

\section{Reference:}

1. Meretoja A, Strbian D, Mustanoja S, Tatlisumak T, Lindsberg PJ, Kaste M. Reducing inhospital delay to 20 minutes in stroke thrombolysis. Neurology. 2012;79(4):306-13.

2. Chalela JA, Kidwell CS, Nentwich LM, Luby M, Butman JA, Demchuk AM, et al. Magnetic resonance imaging and computed tomography in emergency assessment of patients with suspected acute stroke: a prospective comparison. Lancet. 2007;369(9558):293-8.

3. Flynn D, Nesbitt DJ, Ford GA, McMeekin P, Rodgers H, Price C, et al. Development of a computerised decision aid for thrombolysis in acute stroke care. BMC Med Inform Decis Mak. 2015;15:6. 4. McMeekin P, Flynn D, Ford GA, Rodgers H, Gray J, Thompson RG. Development of a decision analytic model to support decision making and risk communication about thrombolytic treatment. BMC Med Inform Decis Mak. 2015;15:90.

5. Nael K, Khan R, Choudhary G, Meshksar A, Villablanca P, Tay J, et al. Six-minute magnetic resonance imaging protocol for evaluation of acute ischemic stroke: pushing the boundaries. Stroke; a journal of cerebral circulation. 2014;45(7):1985-91.

6. Mullins ME, Schaefer PW, Sorensen AG, Halpern EF, Ay H, He J, et al. CT and conventional and diffusion-weighted MR imaging in acute stroke: study in 691 patients at presentation to the emergency department. Radiology. 2002;224(2):353-60. 
7. Thortveit ET, Boe MG, Ljostad U, Mygland A, Tveiten A. Organizational changes aiming to reduce iv tPA door-to-needle time. Acta Neurol Scand. 2014;130(4):248-52.

8. Scherf S, Limburg M, Wimmers R, Middelkoop I, Lingsma H. Increase in national intravenous thrombolysis rates for ischaemic stroke between 2005 and 2012: is bigger better? BMC Neurol. 2016;16:53. 9. Schellinger PD, Jansen O, Fiebach JB, Pohlers O, Ryssel H, Heiland S, et al. Feasibility and practicality of MR imaging of stroke in the management of hyperacute cerebral ischemia. AJNR Am J Neuroradiol. 2000;21(7):1184-9.

10. Singer OC, Sitzer M, du Mesnil de Rochemont R, Neumann-Haefelin T. Practical limitations of acute stroke MRI due to patient-related problems. Neurology. 2004;62(10):1848-9.

11. Yeo LL, Paliwal P, Teoh HL, Seet RC, Chan BP, Wakerley B, et al. Early and continuous neurologic improvements after intravenous thrombolysis are strong predictors of favorable long-term outcomes in acute ischemic stroke. Journal of stroke and cerebrovascular diseases : the official journal of National Stroke Association. 2013;22(8):e590-6.

12. Demchuk AM, Tanne D, Hill MD, Kasner SE, Hanson S, Grond M, et al. Predictors of good outcome after intravenous tPA for acute ischemic stroke. Neurology. 2001;57(3):474-80.

13. Zhang Q, Yang Y, Saver JL. Discharge destination after acute hospitalization strongly predicts three month disability outcome in ischemic stroke. Restor Neurol Neurosci. 2015;33(5):771-5.

14. Smith WS, Lev MH, English JD, Camargo EC, Chou M, Johnston SC, et al. Significance of large vessel intracranial occlusion causing acute ischemic stroke and TIA. Stroke; a journal of cerebral circulation. 2009;40(12):3834-40.

15. Wan JP, Zhang S, Liu KQ, Cai X, Lou YP, Chen ZC, et al. [Risk factors of hemorrhagic transformation in different locations and its relation to clinical outcomes of patients with acute ischemic stroke following intravenous thrombolysis]. Zhejiang Da Xue Xue Bao Yi Xue Ban. 2014;43(1):36-42.

16. Machumpurath B, Davis SM, Yan B. Rapid neurological recovery after intravenous tissue plasminogen activator in stroke: prognostic factors and outcome. Cerebrovasc Dis. 2011;31(3):278-83. 17. Lima FO, Furie KL, Silva GS, Lev MH, Camargo EC, Singhal AB, et al. The pattern of leptomeningeal collaterals on $\mathrm{CT}$ angiography is a strong predictor of long-term functional outcome in stroke patients with large vessel intracranial occlusion. Stroke; a journal of cerebral circulation. 2010;41(10):2316-22.

18. Meretoja A, Weir L, Ugalde M, Yassi N, Yan B, Hand P, et al. Helsinki model cut stroke thrombolysis delays to 25 minutes in Melbourne in only 4 months. Neurology. 2013;81(12):1071-6. 
Tables and figures:

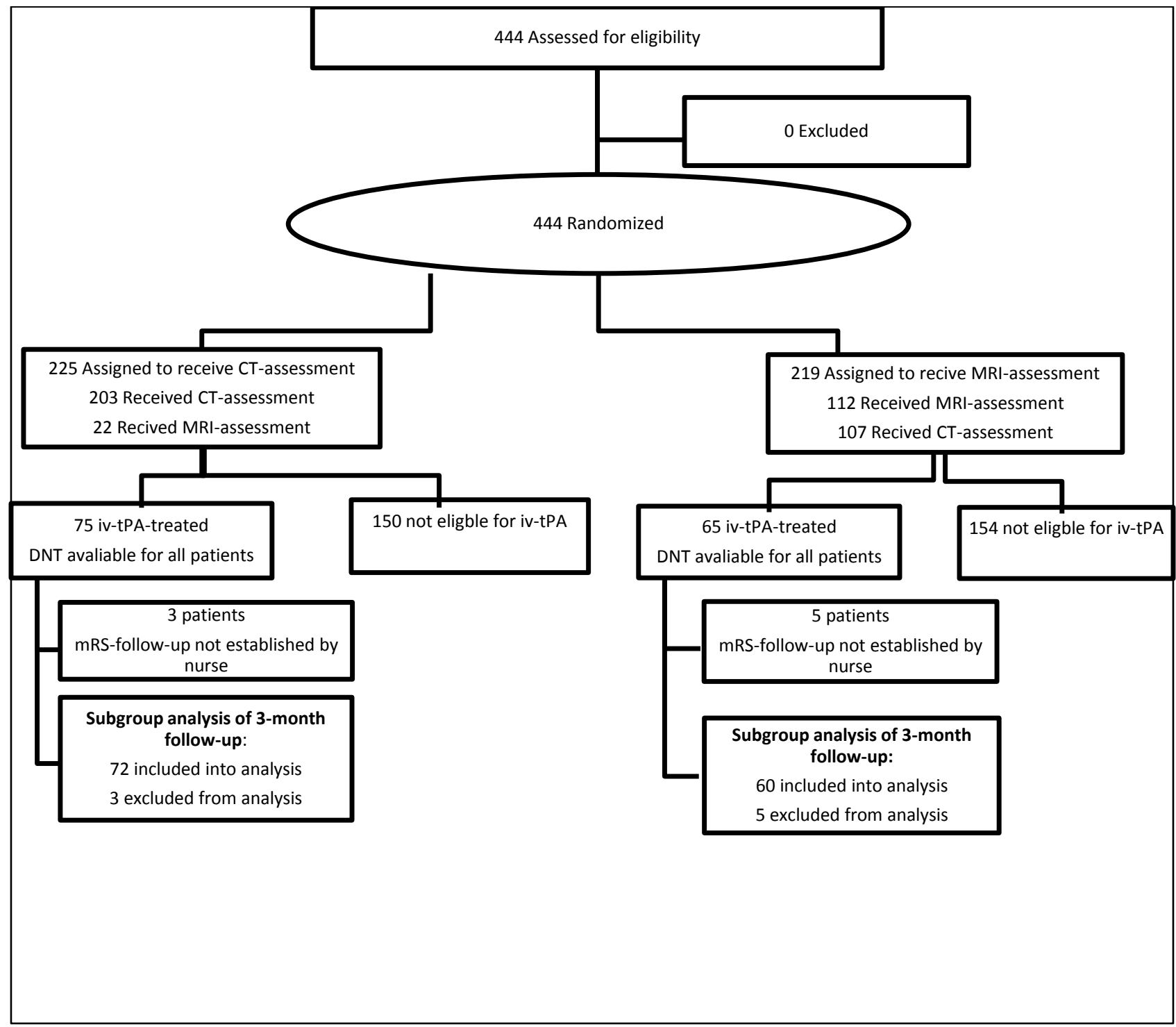

Fig 1. Flow chart of patients.

Door-needle-time (DNT), Intravenous-tissue-Plasminogen-Activator (iv-tPA), modified-Rankin-Scale (mRS), Computer Tomography (CT) and Magnetic Resonance Imaging (MRI). 


\begin{tabular}{|c|c|c|c|}
\hline \multirow[t]{14}{*}{$\begin{array}{l}\text { MRI-allocation } \\
(n=219)\end{array}$} & $\begin{array}{l}\text { Received MRI } \\
(\mathrm{n}=112)\end{array}$ & & \\
\hline & \multirow{13}{*}{$\begin{array}{l}\text { Cross-over to CT } \\
(n=107)\end{array}$} & \multirow{7}{*}{$\begin{array}{l}\text { Contraindications } \\
(n=52)\end{array}$} & Pacemaker $(n=15)$ \\
\hline & & & $\begin{array}{l}\text { Ferromagnetic } \\
\text { implants }(n=5)\end{array}$ \\
\hline & & & $\begin{array}{l}\text { Orbital metal splinters } \\
(n=1)\end{array}$ \\
\hline & & & $\begin{array}{l}\text { Too large body size } \\
(n=8)\end{array}$ \\
\hline & & & Claustrophobia $(n=6)$ \\
\hline & & & $\begin{array}{l}\text { Cervical hyperkyphosis } \\
(\mathrm{n}=2)\end{array}$ \\
\hline & & & $\begin{array}{l}\text { Explicit suspicion } \\
\text { of MRI- } \\
\text { contraindications } \\
(n=15)\end{array}$ \\
\hline & & \multirow[t]{3}{*}{$\begin{array}{l}\text { Clinical condition } \\
(n=40)\end{array}$} & $\begin{array}{l}\text { Critical medical } \\
\text { condition }(n=14)\end{array}$ \\
\hline & & & Physical unrest $(n=17)$ \\
\hline & & & $\begin{array}{l}\text { Need for CT- } \\
\text { angiography including } \\
\text { cervical vessel }(n=9)\end{array}$ \\
\hline & & \multirow[t]{3}{*}{$\begin{array}{l}\text { Organization } \\
(n=15)\end{array}$} & $\begin{array}{l}\text { Waiting time for MRI> } \\
10 \text { minutes }(n=13)\end{array}$ \\
\hline & & & $\begin{array}{l}\text { Close to iv-tPA-window } \\
(n=1)\end{array}$ \\
\hline & & & $\begin{array}{l}\text { Simultaneous arrival of } \\
>1 \text { patient }(n=1)\end{array}$ \\
\hline \multirow[t]{6}{*}{ CT-allocation $(\mathrm{N}=225)$} & Received CT ( $\mathrm{n}=203)$ & & \\
\hline & \multirow[t]{5}{*}{ Cross-over to MRI $(n=22)$} & \multirow[t]{2}{*}{ X-ray-related $(n=6)$} & $\begin{array}{l}\text { Age }<30 \text { years of age } \\
(n=5)\end{array}$ \\
\hline & & & Pregnancy $(n=1)$ \\
\hline & & \multirow[t]{3}{*}{$\begin{array}{l}\text { Needed for diagnostic } \\
\text { clarification }(n=16)\end{array}$} & $\begin{array}{l}\text { Clinical suspicion of } \\
\text { space-occupying tumor } \\
(n=4)\end{array}$ \\
\hline & & & $\begin{array}{l}\text { Diagnostic need for } \\
\text { radiological signs of } \\
\text { acute ischemia in } \\
\text { patients with atypical } \\
\text { clinical presentation } \\
(n=11)\end{array}$ \\
\hline & & & $\begin{array}{l}\text { Suspicion of medullar } \\
\text { compression }(n=1)\end{array}$ \\
\hline
\end{tabular}

Table 1 Cross-overs from allocated image modality 


\begin{tabular}{|l|l|l|l|}
\hline & CT-allocated $\mathrm{n}=225$ & MRI-allocated $\mathrm{n}=219$ & $\mathrm{p}$ \\
\hline Age, years* & $70(26)$ & $70(24)$ & 0.757 \\
\hline Male gender & $97(44.1 \%)$ & $118(53.9 \%)$ & 0.030 \\
\hline NIHSS admission* & $3(7)$ & $3(6)$ & 0.838 \\
\hline mRS before onset* & $1(2)$ & $1(2)$ & 0.743 \\
\hline Thrombolysis & $75(33.3 \%)$ & $65(29.7 \%)$ & 0.468 \\
\hline Endovascular treatment & $7(3.1 \%)$ & $6(2.7 \%)$ & 0.817 \\
\hline Hypertension & $91(40.4 \%)$ & $86(39.3 \%)$ & 0.876 \\
\hline Hypercholesterolemia & $56(24.9 \%)$ & $47(22.4 \%)$ & 0.457 \\
\hline Atrial fibrillation & $35(15.6 \%)$ & $40(18.3 \%)$ & 0.552 \\
\hline Diabetes melitus & $19(8.4 \%)$ & $26(11.9 \%)$ & 0.299 \\
\hline Previous stroke/TIA & $52(23.1 \%)$ & $54(24.7 \%)$ & 0.787 \\
\hline Alcohol abuse & $23(10.2 \%)$ & $21(9.6 \%)$ & 0.974 \\
\hline Use of tobacco & $47(20.9 \%)$ & $42(19.2 \%)$ & 0.777 \\
\hline Discharge diagnosis & & & \\
\hline Ischemic stroke & $96(43.6 \%)$ & $89(40.6 \%)$ & 0.736 \\
\hline TIA & $40(17.8 \%)$ & $42(19.2 \%)$ & 0.797 \\
\hline ICH & $15(6.7 \%)$ & $22(10.0 \%)$ & 0.264 \\
\hline Stroke-mimic & $74(32.9 \%)$ & $66(30.1 \%)$ & 0.502 \\
\hline
\end{tabular}

Table 2, Baseline characteristics for CT and MRI-allocated patients, *median (IQR)

\begin{tabular}{|l|l|l|l|}
\hline & CT performed $n=310$ & MRI performed $n=134$ & $p$ \\
\hline Age* & $73.5(22)$ & $63.5(29.25)$ & 0.001 \\
\hline Male gender & $148(47.7 \%)$ & $67(50 \%)$ & 0.739 \\
\hline NIHSS admission* & $4(10)$ & $2(5)$ & 0.001 \\
\hline mRS before onset* & $1(3)$ & $0(1)$ & 0.001 \\
\hline Thrombolysis & $107(34.5 \%)$ & $33(24.6 \%)$ & 0.051 \\
\hline Endovascular treatment & $12(3.9 \%)$ & $1(0.7)$ & 0.059 \\
\hline Hypertension & $134(43.2 \%)$ & $43(32.1 \%)$ & 0.036 \\
\hline Hypercholesterolemia & $76(24.5 \%)$ & $27(20.1 \%)$ & 0.380 \\
\hline Atrial fibrillation & $56(18.1 \%)$ & $19(14.2 \%)$ & 0.387 \\
\hline Diabetes melitus & $36(11.6 \%)$ & $9(6.7 \%)$ & 0.162 \\
\hline Previous stroke/TIA & $77(24.9 \%)$ & $29(21.6 \%)$ & 0.546 \\
\hline Alcohol abuse & $32(10.3 \%)$ & $12(9.0 \%)$ & 0.798 \\
\hline Use of tobacco & $62(20.0 \%)$ & $77(57.5 \%)$ & 0.980 \\
\hline Discharge diagnosis & & & \\
\hline Ischemic stroke & $140(45.2 \%)$ & $45(33.6 \%)$ & 0.030 \\
\hline TIA & $54(17.4 \%)$ & $28(20.9 \%)$ & 0.463 \\
\hline ICH & $29(9.4 \%)$ & $8(6.0 \%)$ & 0.319 \\
\hline Stroke-mimic & $87(28.1 \%)$ & $53(39.6 \%)$ & 0.023 \\
\hline
\end{tabular}

Table 3, Baseline Characteristics for CT and MRI-examined patients according to imaging performed (crossovered patients included), *median (IQR) 


\begin{tabular}{|l|l|l|l|}
\hline & CT-allocated $n=203$ & MRI-allocated $n=112$ & $p$ \\
\hline Age* & $71(23)$ & $67(26.25)$ & 0.001 \\
\hline Male gender & $92(45.3 \%)$ & $62(55.4 \%)$ & 0.112 \\
\hline NIHSS admission* & $3(8)$ & $2(4)$ & 0.006 \\
\hline mRS before onset* & $1(2)$ & $0(1)$ & 0.001 \\
\hline Thrombolysis & $73(36.0 \%)$ & $31(27.7 \%)$ & 0.170 \\
\hline Hypertension & $88(18.8 \%)$ & $40(35.4 \%)$ & 0.230 \\
\hline Hypercholesterolemia & $55(27.1 \%)$ & $26(23.2 \%)$ & 0.536 \\
\hline Atrial fibrillation & $33(16.3 \%)$ & $17(15.0 \%)$ & 0.929 \\
\hline Diabetes melitus & $19(9.4 \%)$ & $9(8.0 \%)$ & 0.851 \\
\hline Previous stroke/TIA & $48(23.6 \%)$ & $25(22.3 \%)$ & 0.899 \\
\hline Alcohol abuse & $23(11.3 \%)$ & $12(10.7 \%)$ & 0.889 \\
\hline Use of tobacco & $41(36.6 \%)$ & $21(21.4 \%)$ & 0.885 \\
\hline Discharge diagnosis & \multicolumn{3}{|l|}{} \\
\hline Ischemic stroke & $94(46.3 \%)$ & $43(38.4 \%)$ & 0.316 \\
\hline TIA & $34(16.7 \%)$ & $22(19.6 \%)$ & 0.625 \\
\hline ICH & $15(7.4 \%)$ & $8(7.1 \%)$ & 0.936 \\
\hline Stroke-mimic & $60(29.6 \%)$ & $39(34.8 \%)$ & 0.403 \\
\hline Tab &
\end{tabular}

Table 4, Baseline Characteristics for CT and MRI-examined patients according to allocation (cross-overed patients excluded), *median (IQR) 


\begin{tabular}{|c|c|c|c|c|c|c|c|c|c|c|c|}
\hline & & \multirow[b]{2}{*}{$\mathrm{n}$} & \multicolumn{2}{|c|}{ Onset-door-time } & \multicolumn{2}{|c|}{ Door-scan-time } & \multicolumn{2}{|c|}{ Door-decision-time } & \multicolumn{3}{|c|}{ Door-needle-time } \\
\hline & & & Minutes* & $\mathrm{p}$ & Minutes* & $p$ & Minutes* & $\mathrm{p}$ & $n$ & Minutes* & $\mathrm{p}$ \\
\hline \multirow[t]{2}{*}{ All patients } & $\mathrm{CT}$ & 225 & $\begin{array}{l}89 \\
(76)\end{array}$ & \multirow[t]{2}{*}{0.870} & $\begin{array}{l}9 \\
\text { (7) }\end{array}$ & \multirow[t]{2}{*}{0.001} & \begin{tabular}{|l|}
19 \\
$(13)$
\end{tabular} & \multirow[t]{2}{*}{0.001} & & & \\
\hline & MRI & 219 & \begin{tabular}{|l|}
87.0 \\
$(75.0)$ \\
\end{tabular} & & $\begin{array}{l}12 \\
(9.0) \\
\end{array}$ & & \begin{tabular}{|l|}
23 \\
$(15.0)$ \\
\end{tabular} & & & & \\
\hline \multirow[t]{2}{*}{$\begin{array}{l}\text { Ischemic } \\
\text { stroke }\end{array}$} & CT & 96 & \begin{tabular}{|l|}
84.5 \\
$(68)$ \\
\end{tabular} & \multirow[t]{2}{*}{0.629} & $\begin{array}{l}8 \\
(7.5) \\
\end{array}$ & \multirow[t]{2}{*}{0.003} & \begin{tabular}{|l|}
17 \\
$(11)$ \\
\end{tabular} & \multirow[t]{2}{*}{0.009} & 72 & \begin{tabular}{|l|}
22 \\
$(16)$ \\
\end{tabular} & \multirow[t]{2}{*}{0.005} \\
\hline & MRI & 89 & \begin{tabular}{|l|}
80.5 \\
$(77.8)$ \\
\end{tabular} & & $\begin{array}{l}10 \\
(10) \\
\end{array}$ & & \begin{tabular}{|l|}
23 \\
$(13.0)$ \\
\end{tabular} & & 60 & \begin{tabular}{|l|}
30 \\
$(14)$ \\
\end{tabular} & \\
\hline \multirow[t]{2}{*}{$\mathrm{ICH}$} & CT & 15 & \begin{tabular}{|l|}
81 \\
$(45)$ \\
\end{tabular} & \multirow[t]{2}{*}{0.891} & $\begin{array}{l}8 \\
(6.5) \\
\end{array}$ & \multirow[t]{2}{*}{0.169} & \begin{tabular}{|l|}
16 \\
$(9)$ \\
\end{tabular} & \multirow[t]{2}{*}{0.371} & & & \\
\hline & $\mathrm{MRI}$ & 22 & \begin{tabular}{|l|}
75 \\
$(53)$ \\
\end{tabular} & & $\begin{array}{l}13.5 \\
(11.75) \\
\end{array}$ & & \begin{tabular}{|l|}
18.5 \\
$(12)$ \\
\end{tabular} & & & & \\
\hline \multirow[t]{2}{*}{ TIA } & $\mathrm{CT}$ & 40 & $\begin{array}{l}102 \\
(86) \\
\end{array}$ & \multirow[t]{2}{*}{0.937} & $\begin{array}{l}9 \\
(5.25) \\
\end{array}$ & \multirow[t]{2}{*}{0.002} & \begin{tabular}{|l|}
20 \\
$(14.5)$ \\
\end{tabular} & \multirow[t]{2}{*}{0.089} & & & \\
\hline & $\mathrm{MRI}$ & 42 & \begin{tabular}{|l|}
97 \\
$(91.5)$ \\
\end{tabular} & & $\begin{array}{l}13.5 \\
(9) \\
\end{array}$ & & \begin{tabular}{|l|}
25 \\
$(17)$ \\
\end{tabular} & & & & \\
\hline \multirow[t]{2}{*}{$\begin{array}{l}\text { Stroke- } \\
\text { mimics }\end{array}$} & CT & 74 & \begin{tabular}{|l}
92.5 \\
$(93.25)$ \\
\end{tabular} & \multirow[t]{2}{*}{0.859} & $\begin{array}{l}11 \\
(12.5) \\
\end{array}$ & \multirow[t]{2}{*}{0.329} & \begin{tabular}{|l|}
19 \\
$(10.75)$ \\
\end{tabular} & \multirow[t]{2}{*}{0.169} & 3 & 25 & \multirow[t]{2}{*}{0.571} \\
\hline & $\mathrm{MRI}$ & 66 & $\begin{array}{l}107.5 \\
(89.5)\end{array}$ & & $\begin{array}{l}11 \\
(9.25)\end{array}$ & & \begin{tabular}{|l|}
23.5 \\
$(17.5)$ \\
\end{tabular} & & 5 & \begin{tabular}{|l|}
41 \\
$(36)$ \\
\end{tabular} & \\
\hline \multirow{2}{*}{$\begin{array}{l}\text { All iv-tpA- } \\
\text { treated } \\
\text { patients }\end{array}$} & CT & 75 & \begin{tabular}{|l|}
84.5 \\
$(72)$ \\
\end{tabular} & \multirow[t]{2}{*}{0.136} & $\begin{array}{l}8 \\
(6) \\
\end{array}$ & \multirow[t]{2}{*}{0.001} & \begin{tabular}{|l|}
16.5 \\
$(10)$ \\
\end{tabular} & \multirow[t]{2}{*}{0.001} & 75 & \begin{tabular}{|l|}
22 \\
$(15.5)$ \\
\end{tabular} & \multirow[t]{2}{*}{0.004} \\
\hline & MRI & 65 & \begin{tabular}{|l|}
71 \\
$(74)$ \\
\end{tabular} & & $\begin{array}{l}9.75 \\
(9.75) \\
\end{array}$ & & \begin{tabular}{|l|}
23 \\
$(12.0)$ \\
\end{tabular} & & 65 & \begin{tabular}{|l|}
30.0 \\
$(14.0)$ \\
\end{tabular} & \\
\hline
\end{tabular}

Table 5, Time intervals for patients according allocation and discharge diagnosis. *Minutes, median (IQR) 


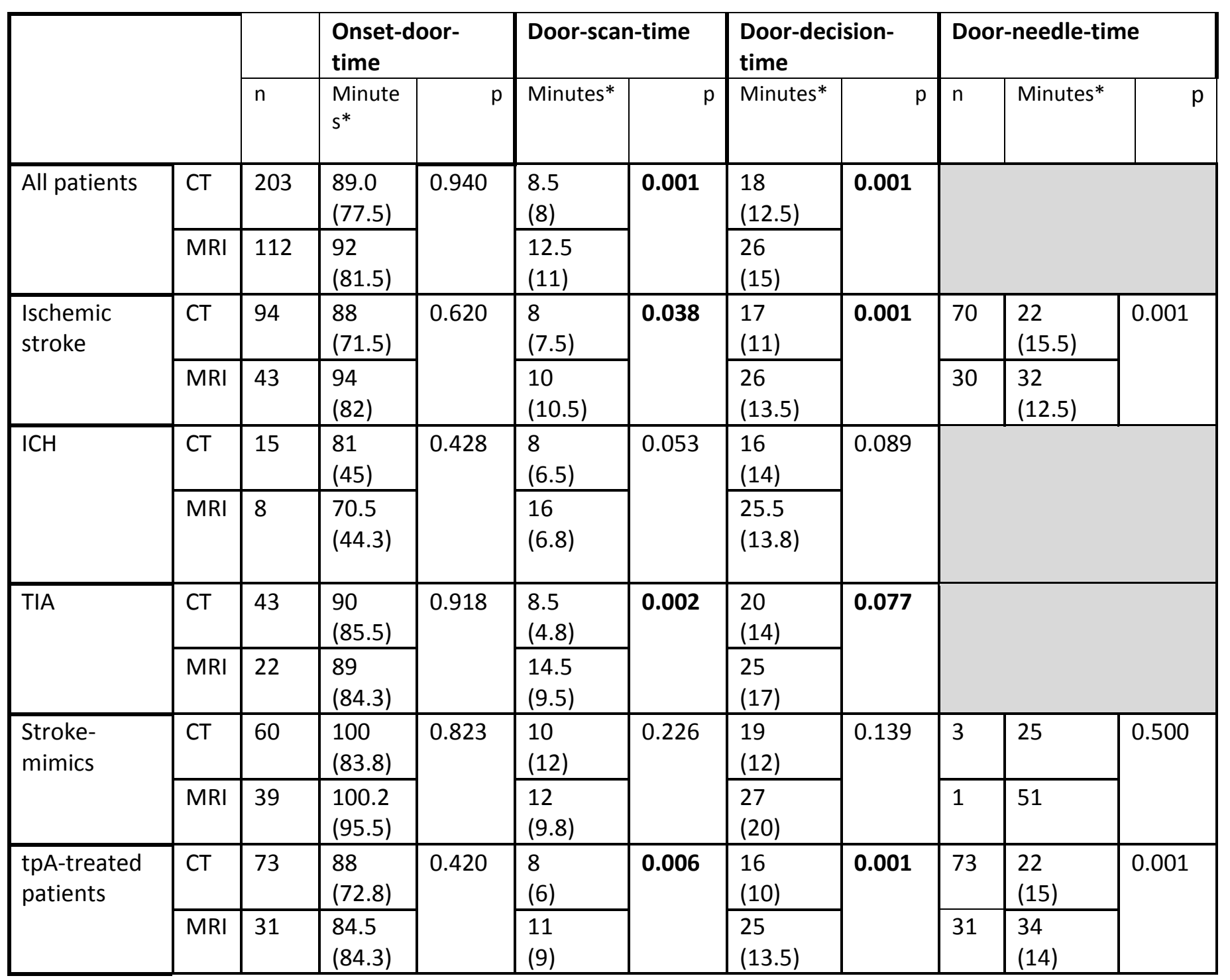

Table 6; Time intervals for patients according to allocation, cross-overed patients excluded. * Minutes, median (IQR) 


\begin{tabular}{|c|c|c|c|c|c|c|c|c|c|c|c|}
\hline & & \multirow[b]{2}{*}{$\mathrm{N}$} & \multicolumn{2}{|c|}{ Onset-door-time } & \multicolumn{2}{|c|}{ Door-scan-time } & \multicolumn{2}{|c|}{$\begin{array}{l}\text { Door-decision- } \\
\text { time }\end{array}$} & \multicolumn{3}{|c|}{ Door-needle-time } \\
\hline & & & Minutes* & $\mathrm{p}$ & Minutes* & $p$ & Minutes* & $\mathrm{p}$ & $\mathrm{n}$ & Minutes* & $\mathrm{p}$ \\
\hline \multirow[t]{2}{*}{ All patients } & CT & 310 & $\begin{array}{l}88.0 \\
(71.0) \\
\end{array}$ & \multirow[t]{2}{*}{0.929} & $\begin{array}{l}10 \\
(7.5) \\
\end{array}$ & \multirow[t]{2}{*}{0.001} & $\begin{array}{l}19 \\
(12) \\
\end{array}$ & \multirow[t]{2}{*}{0.001} & & & \\
\hline & $\mathrm{MRI}$ & 134 & $\begin{array}{l}89.5 \\
(79.8) \\
\end{array}$ & & $\begin{array}{l}12 \\
(10.3) \\
\end{array}$ & & $\begin{array}{l}25 \\
(15) \\
\end{array}$ & & & & \\
\hline \multirow[t]{2}{*}{$\begin{array}{l}\text { Ischemic } \\
\text { stroke }\end{array}$} & CT & 140 & $\begin{array}{l}80.0 \\
(67.0)\end{array}$ & \multirow[t]{2}{*}{0.557} & $\begin{array}{l}9 \\
(7.5)\end{array}$ & \multirow[t]{2}{*}{0.175} & $\begin{array}{l}18 \\
(11.25)\end{array}$ & \multirow[t]{2}{*}{0.001} & 100 & $\begin{array}{l}23 \\
(17.0)\end{array}$ & \multirow[t]{2}{*}{0.002} \\
\hline & $\mathrm{MRI}$ & 45 & $\begin{array}{l}82 \\
(85) \\
\end{array}$ & & $\begin{array}{l}10 \\
(9.8) \\
\end{array}$ & & $\begin{array}{l}26 \\
(13.8) \\
\end{array}$ & & 32 & $\begin{array}{l}32 \\
(14) \\
\end{array}$ & \\
\hline \multirow[t]{2}{*}{$\mathrm{ICH}$} & $\mathrm{CT}$ & 29 & $\begin{array}{l}82.5 \\
(56.5) \\
\end{array}$ & \multirow[t]{2}{*}{0.307} & $\begin{array}{l}10 \\
(8)\end{array}$ & \multirow[t]{2}{*}{0.061} & $\begin{array}{l}16 \\
(8)\end{array}$ & \multirow[t]{2}{*}{0.05} & & & \\
\hline & $\mathrm{MRI}$ & 8 & $\begin{array}{l}70.5 \\
(44.3) \\
\end{array}$ & & $\begin{array}{l}16 \\
(6.8) \\
\end{array}$ & & $\begin{array}{l}25.5 \\
(13.8) \\
\end{array}$ & & & & \\
\hline \multirow[t]{2}{*}{ TIA } & CT & 54 & $\begin{array}{l}100 \\
(88.5)\end{array}$ & \multirow[t]{2}{*}{0.982} & $\begin{array}{l}10 \\
(6.8)\end{array}$ & \multirow[t]{2}{*}{0.009} & $\begin{array}{l}21 \\
(14)\end{array}$ & \multirow[t]{2}{*}{0.170} & & & \\
\hline & $\mathrm{MRI}$ & 28 & $\begin{array}{l}102 \\
(88.5) \\
\end{array}$ & & $\begin{array}{l}13 \\
(9) \\
\end{array}$ & & $\begin{array}{l}25.5 \\
(17.3) \\
\end{array}$ & & & & \\
\hline \multirow[t]{2}{*}{$\begin{array}{l}\text { Stroke- } \\
\text { mimics }\end{array}$} & CT & 87 & $\begin{array}{l}103.5 \\
(80.5) \\
\end{array}$ & \multirow[t]{2}{*}{0.476} & $\begin{array}{l}11 \\
(10) \\
\end{array}$ & \multirow[t]{2}{*}{0.177} & $\begin{array}{l}20 \\
(12) \\
\end{array}$ & \multirow[t]{2}{*}{0.196} & 7 & $\begin{array}{l}25 \\
(27) \\
\end{array}$ & \multirow[t]{2}{*}{0.250} \\
\hline & MRI & 53 & $\begin{array}{l}84.5 \\
(93.3)\end{array}$ & & $\begin{array}{l}12 \\
(10)\end{array}$ & & $\begin{array}{l}22.5 \\
(17)\end{array}$ & & 1 & 51 & \\
\hline \multirow[t]{2}{*}{$\begin{array}{l}\text { tpA-treated } \\
\text { patients }\end{array}$} & CT & 107 & $\begin{array}{l}80 \\
(67.5) \\
\end{array}$ & \multirow[t]{2}{*}{0.511} & $\begin{array}{l}9 \\
(7) \\
\end{array}$ & \multirow[t]{2}{*}{0.036} & $\begin{array}{l}17 \\
(12) \\
\end{array}$ & \multirow[t]{2}{*}{0.001} & 107 & $\begin{array}{l}23.0 \\
(16.5) \\
\end{array}$ & \multirow[t]{2}{*}{0.001} \\
\hline & $\mathrm{MRI}$ & 33 & $\begin{array}{l}78 \\
(84.5)\end{array}$ & & $\begin{array}{l}11 \\
(9)\end{array}$ & & $\begin{array}{l}26 \\
(13.8)\end{array}$ & & 33 & $\begin{array}{l}34 \\
(14)\end{array}$ & \\
\hline
\end{tabular}

Table 7, Time intervals for patients according to imaging conducted, cross-overs included. *Minutes, median (IQR) 


\begin{tabular}{|c|c|c|c|c|}
\hline & Estimate & Standard Error & $95 \% \mathrm{Cl}$ & Significance \\
\hline Intercept & 21.677 & 1.166 & $\begin{array}{l}16.018- \\
29.336\end{array}$ & 0.0001 \\
\hline Age & 0.999 & 1.001 & $0.997-1.002$ & 0.763 \\
\hline Female gender & 1.087 & 1.054 & $0.980-1.208$ & 0.115 \\
\hline $\begin{array}{l}\text { NIHSS on } \\
\text { admission }\end{array}$ & 0.998 & 1.005 & 0.989-1.008 & 0.749 \\
\hline mRS prior onset & 1.009 & 1.022 & $0.967-1.052$ & 0.685 \\
\hline CT allocation* & 0.760 & 1.068 & $0.668-0.864$ & 0.0001 \\
\hline $\begin{array}{l}\text { Cross-over to CT } \\
\text { for MRI-allocated } \\
\text { patients }\end{array}$ & 1.097 & 1.067 & $0.964-1.246$ & 0.153 \\
\hline $\begin{array}{l}\text { Cross-over to } \\
\text { MRI for CT- } \\
\text { allocated } \\
\text { patients }\end{array}$ & 0.952 & 1.139 & $0.737-1.29$ & 0.703 \\
\hline $\begin{array}{l}\text { Neurological } \\
\text { consultant** }\end{array}$ & 1.117 & 1.091 & $0.914-1.366$ & 0.241 \\
\hline $\begin{array}{l}\text { Senior stroke } \\
\text { neurological } \\
\text { consultant** }\end{array}$ & 1.165 & 1.091 & $0.913-1.268$ & 0.093 \\
\hline $\begin{array}{l}\text { Ischemic } \\
\text { stroke*** }\end{array}$ & 1.076 & 1.087 & $0.913-1.144$ & 0.378 \\
\hline $\begin{array}{l}\text { Transitory } \\
\text { Ischemic } \\
\text { Attack*** }\end{array}$ & 1.150 & 1.082 & $0.985-1.343$ & 0.077 \\
\hline $\begin{array}{l}\text { Intracranial } \\
\text { Hemorrhage }\end{array}$ & 0.913 & 1.122 & $0.729-1.144$ & 0.429 \\
\hline $\begin{array}{l}\text { No tPA- } \\
\text { prescribed }\end{array}$ & 1.080 & 1.085 & $0.920-1.269$ & 0.346 \\
\hline $\begin{array}{l}\text { Minutes to } \\
\text { arrival of next } \\
\text { patient, intervals } \\
\text { of } 20 \text { minutes }\end{array}$ & 0.987 & 1.007 & $0.973-1.001$ & 0.077 \\
\hline $\begin{array}{l}\text { Number of } \\
\text { patients } \\
\text { evaluated during } \\
\text { shift }\end{array}$ & 0.993 & 1.024 & $0.948-1.041$ & 0.7769 \\
\hline $\begin{array}{l}\text { Additional } \\
\text { imaging } \\
\text { performed }\end{array}$ & 1.097 & 1.075 & $0.952-1.264$ & 0.200 \\
\hline
\end{tabular}

Table 8 Random effect multilevel model identifying predictors of "door-decision-times" and allowing the cluster effect of the 24 stroke physicians. The dependent variable door-to-decision-time was log10transformed to comply with test assumptions; estimates, Standard Errors and $\mathrm{Cl}$ have been backtransformed.

* Versus MRI-allocation, ${ }^{* *}$ versus Late neurological resident, ${ }^{* * *}$ versus stroke mimic discharge diagnosis 


\begin{tabular}{|c|c|c|c|c|}
\hline & Estimate & $\begin{array}{l}\text { Standard } \\
\text { Error }\end{array}$ & $95 \% \mathrm{Cl}$ & Significance \\
\hline Intercept & 37.350 & 1.350 & $\begin{array}{l}20.587- \\
67.764\end{array}$ & 0.0001 \\
\hline Age & 1.002 & 1.003 & $\begin{array}{l}0.995- \\
1.008\end{array}$ & 0.627 \\
\hline Female gender & 1.189 & 1.096 & $\begin{array}{l}0.991- \\
1.426\end{array}$ & 0.063 \\
\hline $\begin{array}{l}\text { NIHSS on } \\
\text { admission }\end{array}$ & 0.985 & 1.008 & $\begin{array}{l}0.971- \\
1.000\end{array}$ & 0.054 \\
\hline CT-allocation* & 0.730 & 1.123 & $\begin{array}{l}0.5580- \\
0.920\end{array}$ & 0.008 \\
\hline $\begin{array}{l}\text { Cross-over to } \\
\text { CT for MRI- } \\
\text { allocated } \\
\text { patients }\end{array}$ & 1.457 & 1.127 & $\begin{array}{l}0.912- \\
1.468\end{array}$ & 0.226 \\
\hline $\begin{array}{l}\text { Cross-over to } \\
\text { MRI for CT- } \\
\text { allocated } \\
\text { patient }\end{array}$ & 1.111 & 1.416 & $\begin{array}{l}0.557- \\
2.215\end{array}$ & 0.763 \\
\hline $\begin{array}{l}\text { Neurological } \\
\text { consultant** }\end{array}$ & 0.986 & 1.183 & $\begin{array}{l}0.699- \\
1.391\end{array}$ & 0.935 \\
\hline $\begin{array}{l}\text { Senior stroke } \\
\text { neurological } \\
\text { consultant } * *\end{array}$ & 1.077 & 1.221 & $\begin{array}{l}0.971- \\
1.605\end{array}$ & 0.054 \\
\hline $\begin{array}{l}\text { Minutes to } \\
\text { arrival of next } \\
\text { patient, } \\
\text { intervals of } 10 \\
\text { minutes }\end{array}$ & 0.980 & 1.013 & $\begin{array}{l}0.956- \\
1.005\end{array}$ & 0.123 \\
\hline $\begin{array}{l}\text { Number of } \\
\text { patients } \\
\text { evaluated } \\
\text { during shift }\end{array}$ & 0.945 & 1.047 & $\begin{array}{l}0.863- \\
1.035\end{array}$ & 0.219 \\
\hline
\end{tabular}

Table 9 Random effect multilevel model identifying predictors of "door-needle-times" and allowing the cluster effect of the 24 stroke physicians. The dependent variable door-to-decision-time was log10transformed to comply with test assumptions; estimates, Standard Errors and $\mathrm{Cl}$ have been backtransformed.

*versus MRI-allocation performed, **versus Late neurological resident 